\title{
EMPODERAMENTO PSICOLÓGICO DOS PROFISSIONAIS DA SAÚDE
}

\author{
Bianca Gomes Salles*, Flávia Dias, Renata C. Gasparino
}

\section{Resumo}

A palavra empoderamento carrega diferentes conceitos em diferentes áreas do conhecimento, estando relacionado ao significado de controle e segurança sobre determinadas atitudes e o empoderamento psicológico é uma motivação intrínseca do trabalhador para a realização das suas tarefas. Essa pesquisa objetivou avaliar se existem diferenças no empoderamento psicológico entre os diferentes profissionais da saúde. Estudo descritivo, quantitativo e transversal, realizado com 165 profissionais que atuam em um hospital público e de ensino do interior de São Paulo. Os participantes foram agrupados em três grupos: enfermeiros, médicos e outros profissionais (fisioterapeutas, assistentes sociais, psicólogos, nutricionistas, farmacêuticos e fonoaudiólogos). Para a coleta de dados foi utilizada a versão brasileira do Psychological Empowerment Instrument (PEI). Não existem diferenças estatisticamente significantes na percepção do empoderamento psicológico dos diferentes profissionais da saúde, com exceção do domínio competência, no qual os enfermeiros sentem-se menos competentes do que o grupo outros profissionais.

\section{Palavras-chave:}

Poder (psicologia), Autonomia profissional, Profissionais da saúde.

\section{Introdução}

O empoderamento psicológico é uma motivação intrínseca do trabalhador para a realização das suas tarefas, e pode ser avaliado pelo impacto, competência, significado e escolha. Esse termo possui inúmeros significados e para Spreitzer ${ }^{(1)} \circ$ empoderamento psicológico não é um traço de personalidade imutável e duradouro, mas sim formado pelo ambiente de trabalho, ${ }^{(1-2)}$

\section{Objetivo}

Avaliar se existem diferenças no empenho e motivação para o trabalho (empoderamento psicológico) entre os diferentes profissionais da saúde.

\section{Método}

Trata-se de um estudo descritivo, correlacional, quantitativo e transversal realizado em um hospital de ensino do interior de São Paulo. A amostra, aleatória, foi composta por três grupos: enfermeiros, médicos e outros profissionais. Para a coleta de dados foram utilizados uma ficha para caracterizar a amostra e o Psychological Empowerment Instrument (PEI). (3)

\section{Resultados e Discussão}

Participaram deste estudo 165 profissionais da saúde, com idade média de 43,1 anos ( $d p=10,5)$, tempo de experiência na função de 14,9 anos $(d p=10,5)$ e tempo de experiência na instituição de 13,9 anos $(\mathrm{dp}=10,3)$. A maioria era do sexo feminino $112(67,9 \%)$, casada 108 (65,5\%) e 107 (64,8\%) possuíam um único vínculo empregatício. Dentre os participantes, 71 (43,0\%) tinham pós-graduação lato sensu e $73(38,2 \%)$ atuavam em setores críticos do hospital. A avaliação e a comparação do empoderamento psicológico entre as diferentes categorias de profissionais da saúde foram apresentadas na tabela 1 .

A diferença encontrada no domínio competência, revelou, no pós-teste de Dunn, que os enfermeiros se consideram menos competentes quando comparados aos outros profissionais. A competência está relacionada a confiança que 0 indivíduo tem em realizar suas atividades com habilidade e atender as expectativas da instituição.(1) A falta de confiança dos profissionais enfermeiros pode ter relação com a formação, falta de oportunidades adequadas de trabalho, número insuficiente e mal distribuído de profissionais, desvalorização, falta de incentivos financeiros e reconhecimento da liderança. ${ }^{(4)}$

Tabela 1. Comparação do empoderamento psicológico entre as diferentes profissões.

\begin{tabular}{cccccc}
\hline Variável & Função & $\mathbf{n}$ & Média & Desvio-padrão & p-valor \\
Domínio & Enfermeiro & 56 & 18,9 & 2,4 & \\
significado & Médico & 54 & 19,2 & 2,4 & 0,6844 \\
& Outros & 55 & 19,1 & 2,8 & \\
Domínio & Enfermeiro & 56 & 18,8 & 2,3 & \\
competência & Médico & 54 & 19,2 & 2,6 & \multirow{0}{*}{0,0046} \\
& Outros & 55 & 19,9 & 2,1 & \\
Domínio & Enfermeiro & 56 & 17,2 & 2,9 & \\
autodeterminação & Médico & 54 & 15,8 & 3,8 & 0,1776 \\
& Outros & 55 & 16,7 & 3,7 & \\
Domínio & Enfermeiro & 56 & 16,6 & 3,3 & \\
impacto & Médico & 54 & 15,2 & 3,5 & 0,0606 \\
& Outros & 55 & 15,4 & 3,4 & \\
Empoderamento & Enfermeiro & 56 & 71,4 & 8,7 & \\
& Médico & 54 & 69,3 & 10,2 & 0,5959 \\
& Outros & 55 & 71,1 & 9,0 & \\
\hline
\end{tabular}

*p-valor obtido por meio do teste de Kruskal-Wallis.

\section{Conclusões}

Os resultados da pesquisa evidenciaram que não existem diferenças entre as diferentes categoriais profissionais, no que se refere ao empoderamento psicológico, com exceção da dimensão competência que demonstrou que os enfermeiros se sentem menos competentes quando comparados ao grupo "outros profissionais".

\section{Agradecimentos}

Ao Serviço de Apoio ao Estudante (SAE).

Spreitzer GM. Psychological empowerment in the workplace: construct definition, measurement, and validation. Acade Manag J. 1995;38(5):1442-65

2 Thomas KW, Velthouse BA. Cognitive elements of empowerment: an "interpretive" model of intrinsic task motivation. Acade Manag Review. 1990;15(4):666-81.

${ }^{3}$ Schumaher MLN, Alexandre NMC. Translation and cultural adaptation of the psychological empowerment instrument for the Brazilian context. Rev. Min Enferm.2017;21:10-20.

${ }^{4}$ Cassiani SHB, Lira Neto JCG. Nursing Perspectives and the "Nursing Now" Campaign. Rev Bras Enferm.2018;71(5):2351-2. 